\title{
Thermal Conductivity Enhancement of Epoxy by Hybrid Particulate Fillers of Graphite and Silicon Carbide
}

\author{
Krishnamachar Srinivas ${ }^{1 *}$, Mysore Siddalingappa Bhagyashekar ${ }^{2}$ \\ ${ }^{1}$ Department of Mechanical Engineering, Don Bosco Institute of Technology, Bangalore, India \\ ${ }^{2}$ Department of Mechanical Engineering, Raja Rajeshwari College of Engineering, Bangalore, India \\ Email: sri sanj@yahoo.co.in
}

Received 13 February 2015; accepted 2 March 2015; published 5 March 2015

Copyright (C) 2015 by authors and Scientific Research Publishing Inc.

This work is licensed under the Creative Commons Attribution International License (CC BY). http://creativecommons.org/licenses/by/4.0/

cC) (i) Open Access

\section{Abstract}

This paper reports thermal conductivity studies carried out on room temperature cure (RT) epoxy resin (LY556 + HY951) containing three different particulate fillers such as Graphite (Gr) a soft material, Silicon carbide ( $\mathrm{SiC}$ ) a hard material and a hybrid graphite \& silicon carbide (Gr-SiC). The weight fractions of three different fillers were varied from $10 \mathrm{wt} \%$ to $40 \mathrm{wt} \%$ in steps of $10 \%$. Increased filler fraction increases the thermal conductivity of epoxy composites for all the three types of fillers. The results show that the synergic effect of hybrid filler (Gr-SiC) improves the thermal conductivity of epoxy composites compared to that of Graphite or Silicon carbide. The improvement in thermal conductivity for the epoxy hybrid composite containing $20 \% \mathrm{SiC}, 20 \% \mathrm{Gr}$ and $60 \%$ epoxy is $136 \%$ when compared with neat epoxy. Significant improvement in the thermal conductivity is observed for $40 \%$ filled epoxies. The experimental results were compared with analytical models such as Maxwell, Hashin, Hamilton-Crosser, Nielsen, and Cheng-Vachon. The predicted thermal conductivity by analytical models is in agreement with experimental results.

\section{Keywords}

Hybrid Composites, Particulate Epoxy Composite, Thermal Conductivity

\section{Introduction}

Polymers in general have low thermal conductivity due to low atomic density, chemical bonding, complex crystal structure [1] and anharmonicity in molecular vibrations [2]. The heat transfer in non metals occurs by phonon

*Corresponding author.

How to cite this paper: Srinivas, K. and Bhagyashekar, M.S. (2015) Thermal Conductivity Enhancement of Epoxy by Hybrid Particulate Fillers of Graphite and Silicon Carbide. Journal of Minerals and Materials Characterization and Engineering, 3, 76-84. http://dx.doi.org/10.4236/immce.2015.32010 
or lattice vibrations causing thermal resistance [3]. Epoxy as a matrix has a wide applications in the field of engineering. They have some of the favorable properties such as compatibility with many materials, higher thermal and chemical resistance cheaper than other thermosets. However, due to its cross linked structure, epoxies have disadvantages like brittleness, low impact strength, low wear resistance [4]. Epoxies are poor conductors of heat and current. Hence to improve their thermal conductivity, one of the routes is to reinforce particulate fillers. Excellent conductive properties of epoxies have applications in miniature devices managing heat transfer. To improve thermal conductivity, the thermal resistance has to be minimized. A good interfacial adhesion by modifying the filler surface reduces thermal resistance [5]. Further, when the thermal conductivity of the filler is more than 100 times the thermal conductivity of the polymer matrix, there will not be substantial increase in thermal conductivity of the composite [3]. To overcome this, the aspect ratio of the filler has to be increased so as to create conductive paths [6] [7]. The conductive paths can be created by increasing the volume fraction of fillers, increasing the size of particles and use of hybrid fillers. The fillers with large aspect ratio are capable of creating a conductive network [8] [9]. Hence, the present study looks into the modification of epoxy, by incorporation of particulates of $\mathrm{Gr}, \mathrm{SiC}$ and hybrid (Gr-SiC) at various weight fractions to improve thermal conductivity. The Gr is considered as one of the best conductive filler due to its ability to disperse in a matrix, low cost and good thermal conductivity [1]. SiC microfiller is a choice material for high temperature and high power applications, as it has high thermal conductivity and low thermal expansion coefficient [10].

\section{Experimental Details}

\subsection{Materials Selecting a Template}

Micro particulates of Graphite (Gr) supplied by SD fine chem ltd, India having size less than $60 \mu \mathrm{m}$ and particulates of Silicon carbide (SiC) supplied by Gran Silica India, having size less than $20 \mu \mathrm{m}$ (Figure 1) were used as fillers. The host matrix is an epoxy resin of type LY556 (RT cure) and an amine hardener HY951 supplied by Huntsman India Ltd. The resin and hardener were mixed in the weight ratio 10:1.

\subsection{Specimen Preparation and Characterization}

A metallic mould was fabricated to give specimens of $2 \mathrm{~mm}$ thick and $25 \mathrm{~mm}$ diameter which is coin shaped as shown in Figure 2. Before casting, the mould was cleaned thoroughly and a gel coat was applied to the mould. The particulates were preheated to remove any moisture present in it. The predetermined amounts of fillers were dispersed in epoxy resin, stirring continuously till the time of pouring. The cast specimens were allowed to cure in the mould for 24 hours at room temperature. The room temperature cured specimens were post cured for the following schedule of $50^{\circ} \mathrm{C}$ for 30 minutes, $70^{\circ} \mathrm{C}$ for 60 minutes and $85^{\circ} \mathrm{C}$ for 120 minutes. To begin with, unfilled epoxy was cast first. Further, Gr-epoxy, SiC-epoxy and hybrid (Gr-SiC) epoxy composites were cast. The weight fractions of particulates of $\mathrm{Gr}$ and $\mathrm{SiC}$ were varied from $10 \%$ to $40 \%$ (maximum) in steps of $10 \%$. In the next step, hybrid (Gr-SiC) filled epoxy composites were cast containing the filler weight fraction as given below.

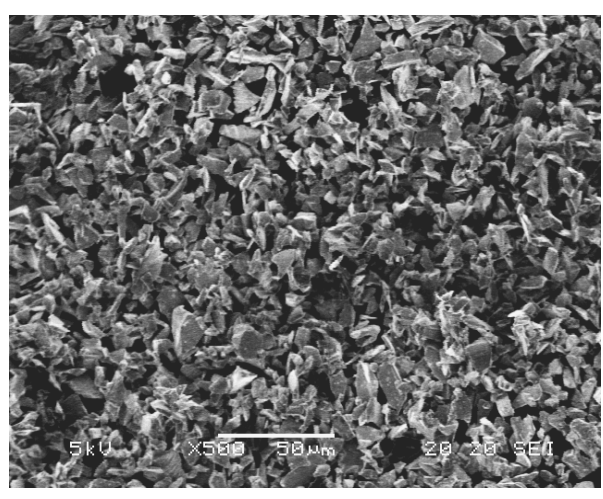

(a)

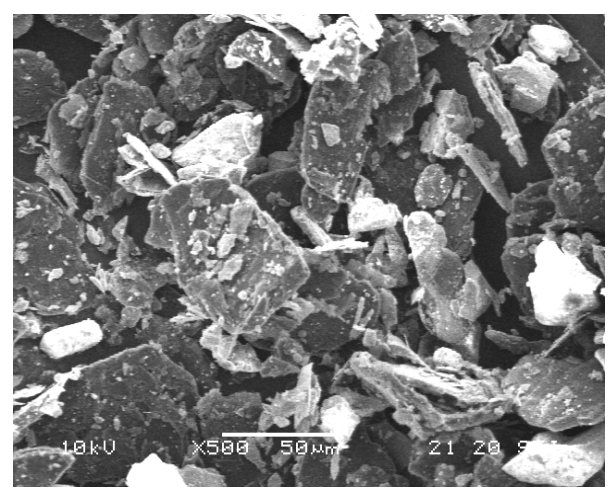

(b)

Figure 1. SEM Photographs of particulates of Gr and SiC. (a) SiC particles; (b) Gr particles. 


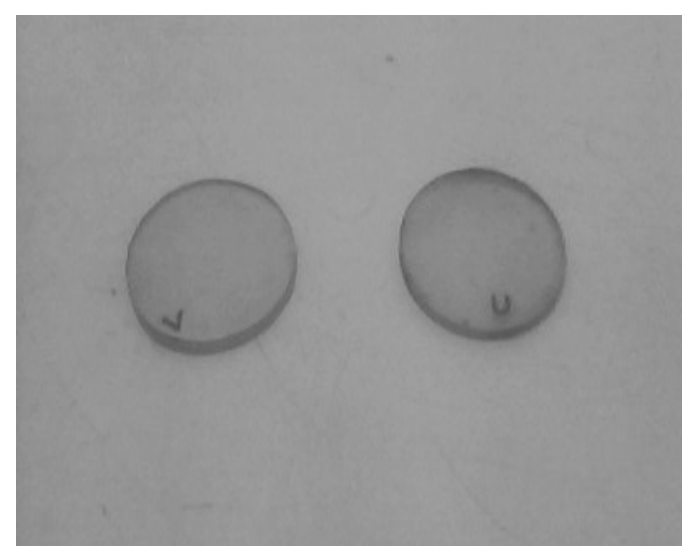

(a)

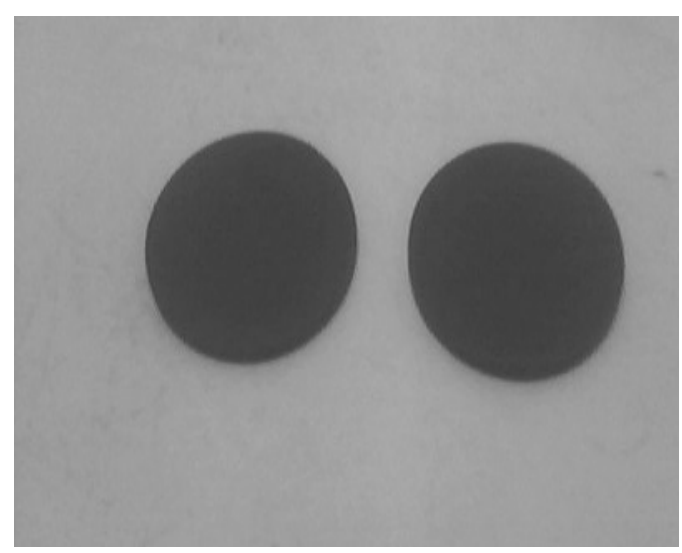

(b)

Figure 2. Cast specimens of epoxy and (Gr-SiC) epoxy hybrid composite. (a) Unfilled epoxy; (b) (Gr-SiC) Hybrid epoxy composite.

Gr fraction kept at 5\%, SiC fraction varied from 5\% to $35 \%$ in steps of $10 \%$.

Gr fraction kept at $10 \%$, SiC fraction varied from $10 \%$ to $30 \%$ in steps of $10 \%$.

SiC fraction kept at 5\%, Gr fraction varied from $5 \%$ to $35 \%$ in steps of $10 \%$.

$\mathrm{SiC}$ fraction kept at $10 \%$, Gr fraction varied from $10 \%$ to $30 \%$ in steps of $10 \%$.

Both $\mathrm{SiC}$ and $\mathrm{Gr}$ fraction varied equally up to $40 \%$ in steps of $10 \%$.

The different types of cast composites along with their codes are presented in Table 1. For ex composite 5S35G-Ep represents particulate content of 5\% SiC, 35\% Gr and 60\% epoxy. Similarly a composite having code 10G30S-Ep has $10 \% \mathrm{Gr}, 30 \% \mathrm{SiC}$ and $60 \%$ epoxy.

\subsection{Measurement of Thermal Conductivity}

Thermal conductivity measurements were carried out by an instrument developed by Indian national academy of science. The schematic diagram of the set up is shown in Figure 3. The thermal conductivity measurements were based on steady state method. One directional heat flow was considered for measurement of thermal conductivity.

\subsection{Description of the Apparatus}

A heater made of six 120-Ohm 1/4 W resistors in parallel is placed in the copper cup of $25 \mathrm{~mm}$ diameter. It is connected to a constant current source. Two cast specimens are clamped between the copper cup and two square copper plates. Two junctions of a copper constantan thermocouple are fixed to upper half of the copper heater cup and to the upper square plate. Another pair of junctions of the thermocouple is fixed to bottom edge of the bottom half of the heater cup and bottom square plate. The leads from the thermocouple are connected to the differential amplifier. The specimens are fixed in between the square plate and the copper cup. The set up is connected to a constant current source. The outputs from the thermocouples are connected to a DC differential amplifier. Initially the current is set at $140 \mathrm{~mA}$. The steady state is obtained after $45 \mathrm{mins}$. The output voltage is measured on a digital multimeter for thermocouple 1 and the process is repeated for thermocouple 2. Further the current is increased to $160 \mathrm{~mA}$ and the measurements are repeated. The measurements are repeated for five different current settings and two specimens were used for each experiment.

The experimental thermal conductivity is evaluated using the equation

$$
Q=-K A\left[\frac{\Delta T}{d}\right]
$$

where, $K$ is the thermal conductivity of composite in $\mathrm{W} / \mathrm{mK}$;

$Q$ is the heat supplied in watts;

$A$ is the area of the specimen in $\mathrm{m}^{2}$;

$d$ is the thickness of the specimen in $\mathrm{m}$. 


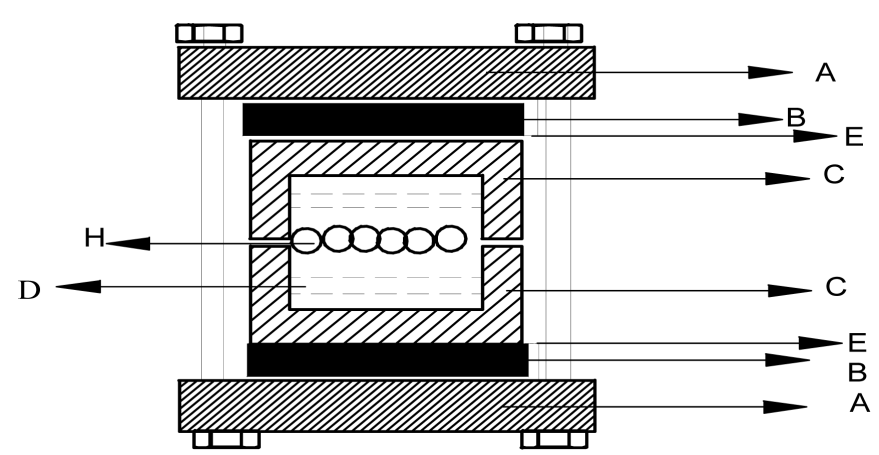

Figure 3. Schematic Diagram of the set up. A: Copper base plate each $50 \mathrm{~mm}$ square $5 \mathrm{~mm}$ thick; B: Specimen $25 \mathrm{~mm}$ dia and $2 \mathrm{~mm}$ thick; C: Two halves of a copper cup $25 \mathrm{~mm}$ dia, outer height $5 \mathrm{~mm}$ and inner height $3 \mathrm{~mm}$; D: Aluminium foils pads; H: Heater made up of six $120 \mathrm{ohm} \mathrm{1/4} \mathrm{W}$ resistors in parallel; E: Cu-Constantan thermocouples.

Table 1. Thermal conductivity of epoxy and its composites.

\begin{tabular}{|c|c|c|c|c|c|c|c|c|c|}
\hline & Code & $\%$ Ep & $\% \mathrm{SiC}$ & $\% \mathrm{Gr}$ & $\begin{array}{c}\text { Expt } \\
(\mathrm{W} / \mathrm{mK})\end{array}$ & $\begin{array}{c}\text { Series } \\
(\mathrm{W} / \mathrm{mK})\end{array}$ & $\begin{array}{l}\text { Maxwell } \\
(\mathrm{W} / \mathrm{mK})\end{array}$ & $\begin{array}{l}\text { Hashin } \\
(\mathrm{W} / \mathrm{mK})\end{array}$ & $\begin{array}{l}\text { Neilson } \\
(\mathrm{W} / \mathrm{mK})\end{array}$ \\
\hline \multirow{4}{*}{$\begin{array}{l}\text { Epoxy and } 10 \% \\
\text { Filled epoxy }\end{array}$} & Ep & 100 & 0 & 0 & 0.30 & 0.30 & 0.30 & 0.30 & 0.30 \\
\hline & 10G-Ep & 90 & 0 & 10 & 0.32 & 0.33 & 0.39 & 0.37 & 0.39 \\
\hline & 10S-Ep & 90 & 10 & 0 & 0.33 & 0.33 & 0.39 & 0.37 & 0.38 \\
\hline & 5S5G-Ep & 90 & 5 & 5 & 0.33 & 0.39 & 0.37 & 0.38 & 0.33 \\
\hline \multirow{5}{*}{ 20\% Filled epoxy } & 20G-Ep & 80 & 0 & 20 & 0.46 & 0.37 & 0.48 & 0.47 & 0.51 \\
\hline & 20S-Ep & 80 & 20 & 0 & 0.41 & 0.37 & 0.49 & 0.45 & 0.49 \\
\hline & 5S15G-Ep & 80 & 5 & 15 & 0.46 & 0.48 & 0.45 & 0.52 & 0.40 \\
\hline & 5G15S-Ep & 80 & 15 & 5 & 0.46 & 0.48 & 0.45 & 0.52 & 0.40 \\
\hline & 10S10G-Ep & 80 & 10 & 10 & 0.51 & 0.48 & 0.45 & 0.50 & 0.37 \\
\hline \multirow{7}{*}{ 30\% Filled epoxy } & 30G-Ep & 70 & 0 & 30 & 0.54 & 0.43 & 0.57 & 0.59 & 0.7 \\
\hline & 30S-Ep & 70 & 30 & 0 & 0.51 & 0.43 & 0.58 & 0.56 & 0.63 \\
\hline & 5S25G-Ep & 70 & 5 & 25 & 0.52 & 0.57 & 0.56 & 0.67 & 0.43 \\
\hline & 5G25S-Ep & 70 & 20 & 5 & 0.52 & 0.57 & 0.56 & 0.67 & 0.43 \\
\hline & 10S20G-Ep & 70 & 10 & 20 & 0.56 & 0.54 & 0.55 & 0.72 & 0.45 \\
\hline & 10G20S-Ep & 70 & 20 & 10 & 0.54 & 0.54 & 0.55 & 0.64 & 0.45 \\
\hline & 15G15S-Ep & 70 & 15 & 15 & 0.58 & 0.60 & 0.59 & 0.69 & 0.45 \\
\hline \multirow{7}{*}{ 40\% Filled epoxy } & 40G-Ep & 60 & 0 & 40 & 0.64 & 0.50 & 0.66 & 0.73 & 1.04 \\
\hline & 40S-Ep & 60 & 40 & 0 & 0.68 & 0.50 & 0.70 & 0.70 & 0.82 \\
\hline & 5S35G-Ep & 60 & 5 & 35 & 0.64 & 0.66 & 0.70 & 0.86 & 0.50 \\
\hline & 5G35S-Ep & 60 & 35 & 5 & 0.62 & 0.66 & 0.70 & 0.86 & 0.50 \\
\hline & 10S30G-Ep & 60 & 10 & 30 & 0.62 & 0.66 & 0.7 & 1.02 & 0.53 \\
\hline & 10G30S-Ep & 60 & 30 & 10 & 0.61 & 0.66 & 0.70 & 0.84 & 0.53 \\
\hline & 20G20S-Ep & 60 & 20 & 20 & 0.71 & 0.71 & 0.70 & 0.90 & 0.50 \\
\hline
\end{tabular}




\subsection{Theoretical Models}

The following analytical models were used to predict the thermal conductivity of epoxy composites [11] [12]. The models considered were Maxwell equation, cylinder assemblage model developed by Hashin Nielsen's equation and series equation, which is an inverse rule of mixtures which gives lower bound values of thermal conductivity for particulate filled composites [12].

a) Maxwell Equation

$$
\frac{K}{K c}=1+\left[\frac{3(K d-K c)}{(K d+2 K c)}\right] \Phi
$$

where $K, K c$ and $K d$ are the thermal conductivities of composites, matrix and fillers $\Phi$ is the volume fraction of filler.

b) Cylinder assemblage model: Cylinder Assemblage model was developed by Hashin

$$
K_{T}=K_{T M}\left\{K_{T M} V_{M}+K_{T F}\left(1+V_{F}\right) / K_{T M}\left(1+V_{F}\right)+K_{T F} V_{M}\right\}
$$

where, $K_{T}, K_{T M}$ and $K_{T F}$ are thermal conductivities of composite, matrix and filler.

$\mathrm{V}_{\mathrm{F}}, \mathrm{V}_{\mathrm{M}}$ are the volume fraction of filler and matrix.

c) Nielsen's Equation

$$
\frac{K_{c}}{K_{m}}=\frac{1+A B \varphi}{1-\phi B \varphi}
$$

where

$$
B=\frac{k_{f} / k_{m}-1}{k_{f} / k_{m}+A} \text { and } \phi=1+\frac{\left(1-\varphi_{\max }\right) \varphi}{\varphi_{\text {max }}^{2}}
$$

where $A$ is the geometry of the particles $=1.5$ and $\phi_{\max }$ (maximum packing fraction)

d) Inverse rule of mixtures/Series

$$
\frac{1}{K_{T}}=\frac{V_{f}}{K_{f}}+\frac{V_{m}}{K_{m}}
$$

The above equation is derived from rule of mixtures and does not consider voids.

\section{Results and Discussion}

\subsection{Effect of Gr/SiC on Thermal Conductivity of Gr-Epoxy/SiC-Epoxy Composites}

The experimental thermal conductivity and predicted by analytical models of all types of epoxy composites is listed in Table 1. Figure 4(a) and Figure 4(b) presents the thermal conductivity of epoxy composites filled with particulates of $\mathrm{Gr}$ and $\mathrm{SiC}$. Neat epoxy exhibits a thermal conductivity of $0.30 \mathrm{~W} / \mathrm{mK}$. For filled $\mathrm{Gr} / \mathrm{SiC}$ epoxy, up to $10 \%$ filler fraction, the rise in thermal conductivity is not significant. The epoxy composites containing $10 \%$ fillers, 10G-Ep and 10S-Ep exhibits a thermal conductivity of $0.32 \mathrm{~W} / \mathrm{mK}$ and $0.33 \mathrm{~W} / \mathrm{mK}$ respectively which is an insignificant improvement over neat epoxy. This may be due to low filler fraction and hence effective conductive paths are not created in the composite. Further addition of particulates of graphite increases thermal conductivity of graphite epoxy composites linearly. The thermal conductivity increases to $0.46 \mathrm{~W} / \mathrm{mK}$ and 0.54 W/mK for 20G-Ep and 30G-Ep respectively. Maxima of $0.64 \mathrm{~W} / \mathrm{mK}$ was observed for 40G-Ep which is an improvement of $113 \%$ over unfilled epoxy. The effect of adding SiC to epoxy is shown in Figure 4(b). The SiC-epoxy composites have trends similar to Gr-epoxy composites. However, 20S-Ep and 30S-Ep have thermal conductivity of $0.41 \mathrm{~W} / \mathrm{mK}$ and $0.51 \mathrm{~W} / \mathrm{mK}$ respectively which is marginally lower than Gr-epoxy under similar loading. However 40S-Ep, exhibits a thermal conductivity of $0.68 \mathrm{~W} / \mathrm{mK}$. This suggests that even though the thermal conductivity of $\mathrm{SiC}(280 \mathrm{~W} / \mathrm{mK})$ is higher than $\mathrm{Gr}(85 \mathrm{~W} / \mathrm{mK})$, SiC-Ep composites have lower thermal conductivity than Gr-Ep composites. The factors such as larger particle size of Gr (20 - $60 \mu \mathrm{m})$ (Figure 1(b)) irregularity in shape, easy dispersibility [11] favors enhancement of thermal conductivity, where as SiC particulates are smaller in size (6 - $12 \mu \mathrm{m})$ uniform (Figure 1), are not beneficial in creating conductive paths [8] [9]. 


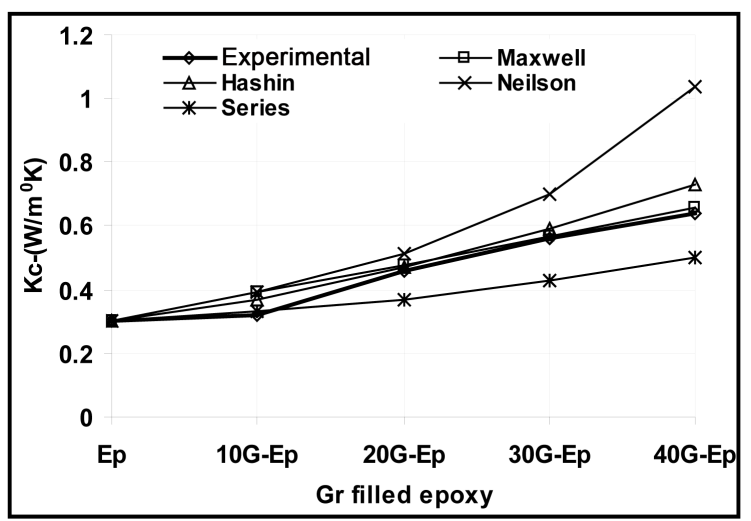

(a)

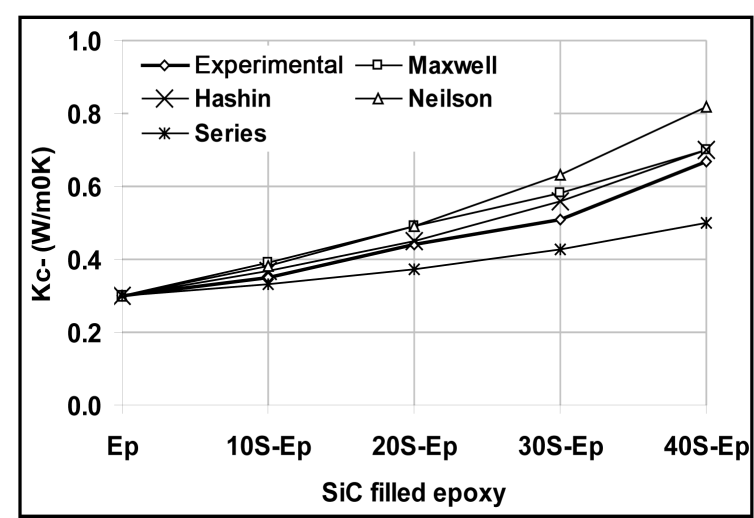

(b)

Figure 4. Thermal conductivity of Gr/SiC filled epoxy. (a) Gr filled epoxy; (b) SiC filled epoxy.

Comparing thermal conductivity experimental with thermal conductivity predicted by analytical equations, it is seen that, series equation predicts lower thermal conductivity for all filler loadings where as Hashin and Maxwell equations are closer to experimental values. The prediction by Nielsen's equation is in agreement with experimental value up to $20 \%$ filler loading and deviates after $30 \%$ filler fraction. This is in agreement with [3] [5], where the Nielsen's estimation at lower volume fraction matches the experimental values and tends to over estimate the thermal conductivity of composites at higher volume fraction.

\subsection{Effect of Gr on Thermal Conductivity of Hybrid (Gr-SiC)-Epoxy Composites}

The effect of varying Gr on hybrid (Gr-SiC) epoxy composites is shown in Figure 5(a) and Figure 5(b). Figure 5(a) shows the thermal conductivity of epoxy composites, where SiC was unvaried at 5\% for all composites, Gr varied from $5 \%$ to $35 \%$ in steps of $10 \%$. Increased $\mathrm{Gr}$ fraction increases the thermal conductivity of hybrid (Gr-SiC) epoxy composites. Thermal conductivity increases to $0.46 \mathrm{~W} / \mathrm{mK}$ for 5S15G-Ep, $0.52 \mathrm{~W} / \mathrm{mK}$ for 5S25G-Ep and $0.64 \mathrm{~W} / \mathrm{mK}$ for 5S35G-Ep composite.

The effect of $\mathrm{Gr}$ where $\mathrm{SiC}$ is held at $10 \%$ and $\mathrm{Gr}$ is varied from $10 \%$ to $30 \%$ is shown in Figure 5 (b). These composites present a trend similar to previous compositions. However, these composites exhibits marginally lower conductivity values than composites having 5\% SiC unvaried composites. Maximum thermal conductivity of $0.62 \mathrm{~W} / \mathrm{mK}$ was observed for 10S30G-Ep. The SEM of the surfaces of 5S35G-Ep and 10S30G-Ep is shown in Figure 6(a) and Figure 6(b) respectively. The few bright spots seen in the images are particulates of SiC.

\subsection{Effect of SiC on Thermal Conductivity of Hybrid (Gr-SiC)-Epoxy Composites}

Figure 7(a) and Figure 7(b) illustrates the effect of varying SiC and holding Gr constant at 5\%, 10\% respectively on hybrid (Gr-SiC) epoxy composites. Thermal conductivity increases linearly for all type of composites. The thermal conductivity increases to $0.52 \mathrm{~W} / \mathrm{mK}$ for 5G25S-Ep and $0.62 \mathrm{~W} / \mathrm{mK}$ for 5G35S-Ep. Similarly 10G20S-Ep and 10G30S-Ep exhibits thermal conductivity of $0.54 \mathrm{~W} / \mathrm{mK}$ and $0.62 \mathrm{~W} / \mathrm{mK}$ respectively. The SEM images of 5G35S-Ep and 10G30S-Ep composites are shown in Figure 8(a) and Figure 8(b). As SiC fraction is more for these composites, more bright spots are seen, indicating well distribution of SiC.

\subsection{Effect of Equal Fraction of $\mathrm{Gr}$ and $\mathrm{SiC}$ on Thermal Conductivity of Hybrid (Gr-SiC)-Epoxy Composites}

The effect of hybrid (Gr-SiC) fillers on epoxy where both fillers are equally varied is shown in Figure 9. The thermal conductivity of 10G10S-Ep is found to be $0.51 \mathrm{~W} / \mathrm{mK}$ which is highest among $20 \%$ filled composites. Similarly 15G15S-Ep exhibits a thermal conductivity of $0.58 \mathrm{~W} / \mathrm{mK}$, highest among 30\% filled epoxy. Similarly the thermal conductivity of 20G20S-Ep is $0.71 \mathrm{~W} / \mathrm{mK}$, highest among $40 \%$ filled composites. Further, it is also observed that for the same filler loadings, the thermal conductivity varies. As filler loading increases, number of interfaces increases and thermal conductivity in a polymer composite is dependent on good interfacial adhesion. For a poor interfacial adhesion phonon scattering increases, and decreases the thermal conductivity. Further dif- 


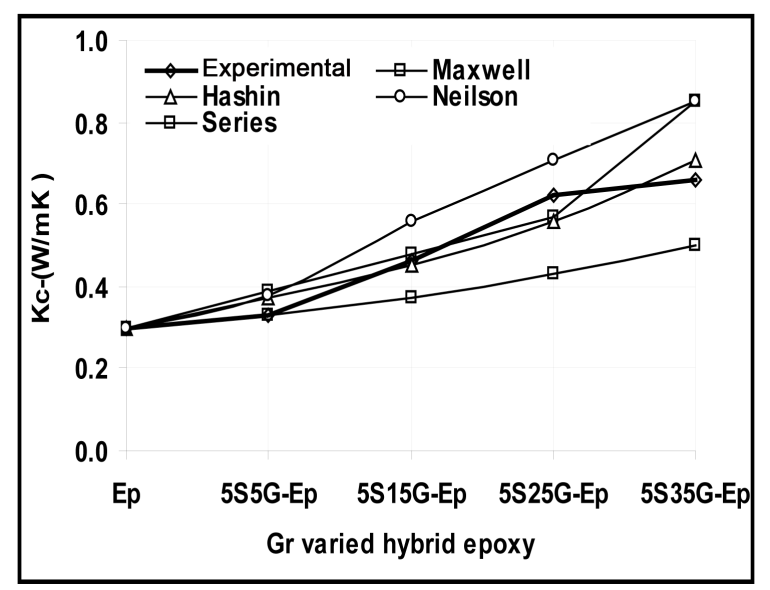

(a)

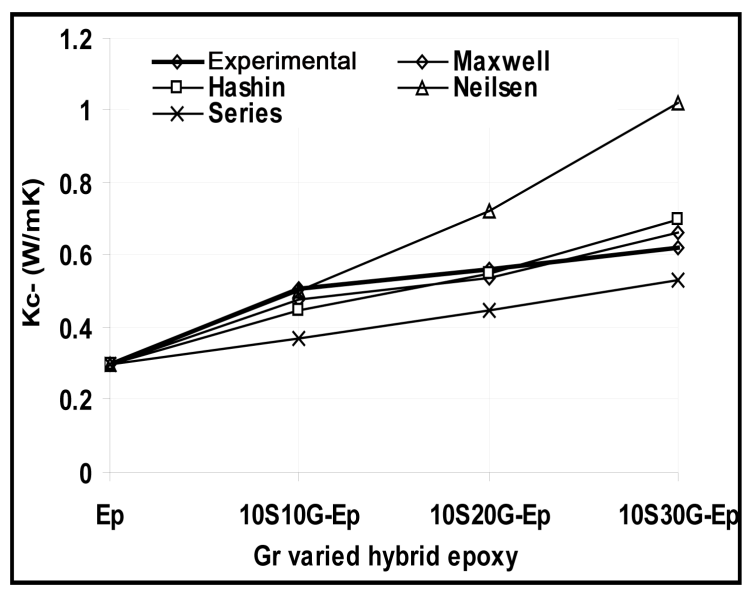

(b)

Figure 5. Thermal conductivity of graphite rich hybrid (Gr-SiC) epoxy composites. (a) SiC constant at 5\%, Gr varied from $5 \%$ - 35\%; (b) SiC constant at 10\%, Gr varied from $10 \%-30 \%$.

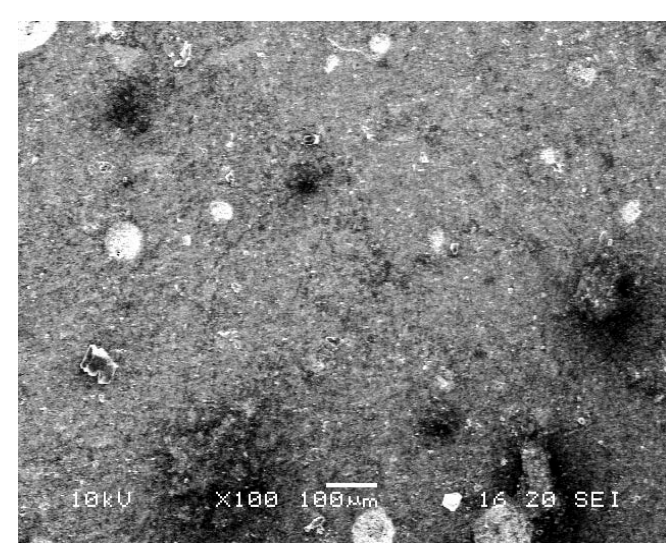

(a)

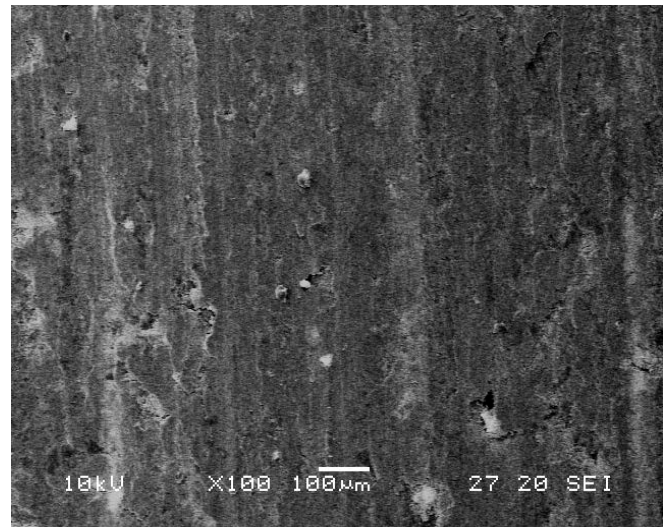

(b)

Figure 6. SEM images of surface of graphite rich hybrid (Gr-SiC) epoxy composites. (a) 5S35G-Ep; (b) 10S30G-Ep.

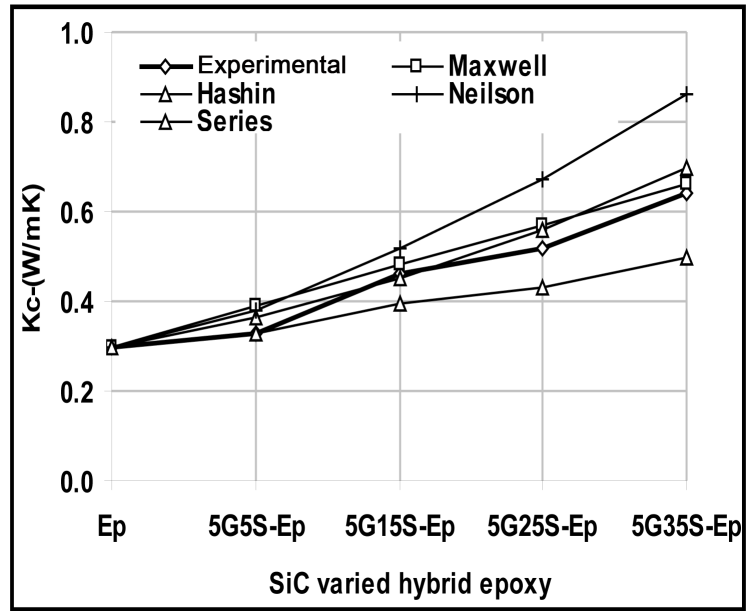

(a)

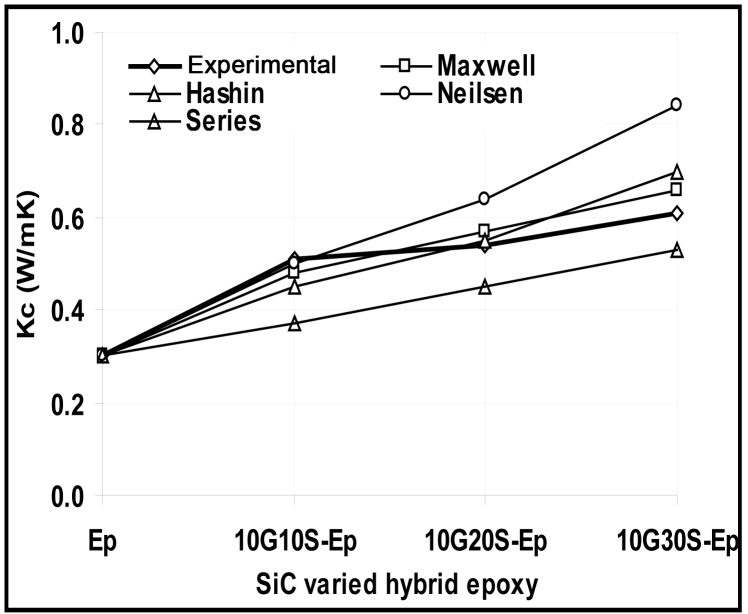

(b)

Figure 7. Thermal conductivity of SiC rich hybrid (Gr-SiC) epoxy composites. (a) Gr constant at 5\%, SiC varied from $5 \%$ - 35\%; (b) Gr constant at 10\%, SiC varied from $10 \%-30 \%$. 


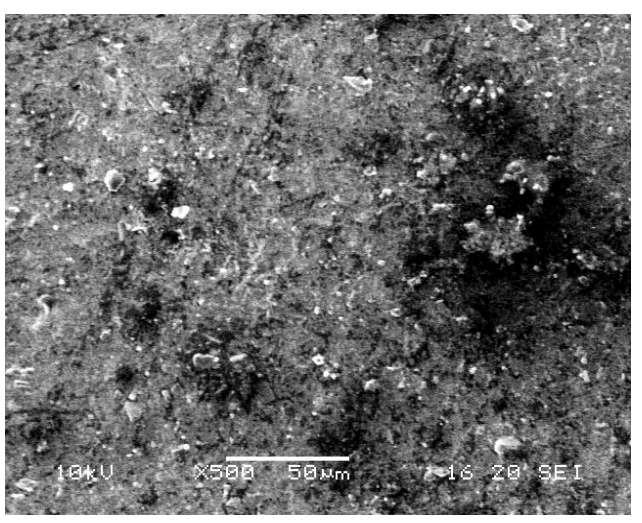

(a)

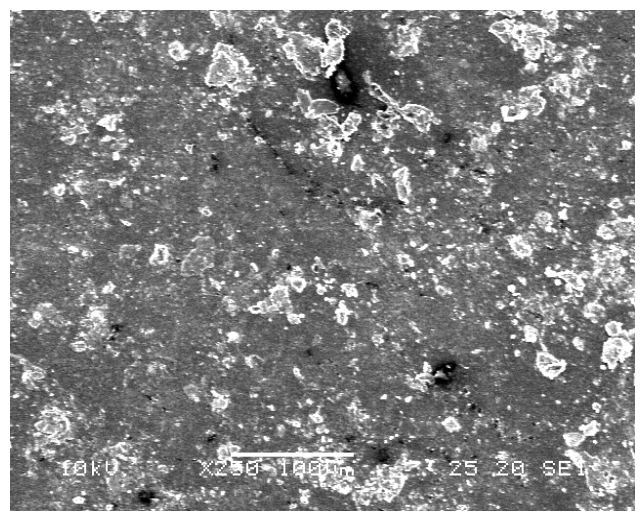

(b)

Figure 8. SEM images of surface of graphite rich hybrid (Gr-SiC) epoxy composites. (a) 5G35S-Ep; (b) 10G30S-Ep.

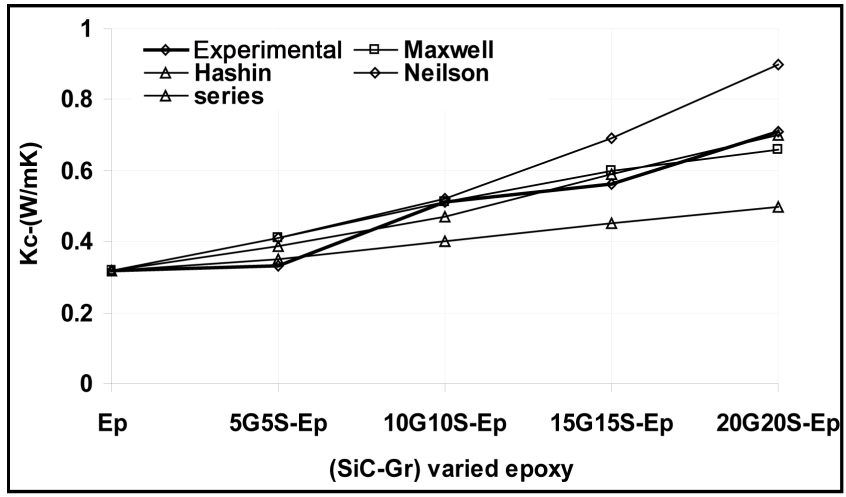

Figure 9. Effect of fillers on thermal conductivity of epoxy composites. Both $\mathrm{Gr}$ and $\mathrm{SiC}$ varied equally.

ferent particle sizes vary the interfaces along the heat transfer path [13]. From the above it is evident that synergy exists between hybrid (Gr-SiC) when both the fillers are loaded equally.

\section{Conclusion}

Thermal conductivity increases linearly with increased filler fraction for all composite systems irrespective of fillers. Thermal conductivity show significant increase after 20\% filler fraction. Comparing Gr-Ep and SiC-Ep composites, for the same filler fraction, Gr-Ep composites have higher thermal conductivity than SiC-Ep composites except for 40S-Ep which has higher thermal conductivity than 40G-Ep. Hybrid composites having equal proportion of filler fraction i.e. 10G10S-Ep, 15G15S-Ep and 20G20S-Ep have thermal conductivity highest in $20 \%$, 30\% and $40 \%$ filled epoxy composites. The hybrid composite 20G20S-Ep has a thermal conductivity of $0.71 \mathrm{~W} / \mathrm{mK}$ which is highest among all the composite considered in this study and is an improvement of $136 \%$ over a neat epoxy. The experimental results were compared with the analytical models. The experimental results exhibit good correlation with Maxwell's equation.

\section{Acknowledgements}

The authors thank the management of Don Bosco Institute of Technology, RajaRajeswari College of Engineering Bangalore and Indian Academy Of Science. Bangalore.

\section{References}

[1] Ebadi-Dehaghani, H. and Branch, M.N.S. (2012) Thermal Conductivity of Nanoparticles Filled Polymers Islamic Azad 
University Iran Smart Nanoparticles Technology. 519-540.

[2] Tsekmes, I.A., Kochetov, R., Morshuis, P.H.F. and Smit, J.J. (2013) Thermal Conductivity of Polymeric Composites: A Review. 2013 IEEE International Conference on Solid Dielectrics, Bologna, 30 June-4 July 2013, 678-681.

[3] Leea, G.-W., Parka, M., Kima, J., Leeb, J.I. and Yoonb, H.G. (2006) Enhanced Thermal Conductivity of Polymer Composites Filled with Hybrid Filler. Composites: Part A, 37, 727-734. http://dx.doi.org/10.1016/j.compositesa.2005.07.006

[4] Wang, M.C., Zhang, Z.G. and Sun, Z.J. (2009) The Hybrid Model and Mechanical Properties of Hybrid Composites Reinforced with Different Diameter Fibers. Journal of Reinforced Plastics and Composites, 28, 257.

[5] Kanga, S., Honga, S.I., Choeb, C.R., Parkb, M., Rimb, S. and Kimb, J. (2001) Preparation and Characterization of Epoxy Composites Filled with Functionalized Nanosilica Particles Obtained via Solgel Process. Polymer, 42, 879-887. http://dx.doi.org/10.1016/S0032-3861(00)00392-X

[6] Luyt, A.S., Molefi, J.A. and Krump, H. (2005) Thermal Mechanical and Electrical Properties of Copper Filled Low Density Ald Linear Low Density Polyethylene Composites. Polymer Degradation and Stability, 1-8.

[7] Yung, K.C., Wang, J. and Yue, T.M. (2008) Thermal Management for Boron Nitride Filled Metal Core Printed Circuit Board. Journal of Composite Materials, 42, 2615. http://dx.doi.org/10.1177/0021998308096326

[8] Zhou, W.Y., Wang, C.F., An, Q.L. and Ou, H.Y. (2008) On Thermal Properties of Heat Conductive Silicone Rubber Filled with Hybrid Fillers. Journal of Composite Materials, 42, 173.

[9] Mamunya, Ye.P., Davydenko, V.V., Piss, P. and Lebedev, E.V. (2002) Electrical and Thermal Conductivity of Polymers Filled with Metal Powders. European Polymer Journal, 38, 1887-1897. http://dx.doi.org/10.1016/S0014-3057(02)00064-2

[10] Zhou1, T., Wang, X., Cheng, P., Wang, T., Xiong, D. and Wang, X. (2013) Improving the Thermal Conductivity of Epoxy Resin by the Addition of a Mixture of Graphite Nanoplatelets and Silicon Carbide Microparticles. Express Polymer Letters, 7, 585-594. http://dx.doi.org/10.3144/expresspolymlett.2013.56

[11] Reine, B., Tomaso, J.D., Dusserre, G. and Olivier, P.A. (2012) Study of Thermal Behaviour of Thermoset Polymer Matrix Filled with Micro and Nano Particles. Proceedings of ECCM15, Italy, 24-28 June 2012.

[12] Pal, R. (2007) New Models for Thermal Conductivity of Particulate Composites. Journal of Reinforced Plastics and Composites, 26, 643. http://dx.doi.org/10.1177/0731684407075569

[13] Hong, J.-P., Yoon, S.-W., Hwang, T.-S., Lee, Y.-K., Won, S.-H. and Nam, J.-D. (2010) Inter Phase Control of Boron Nitride/Epoxy Composites for High Thermal Conductivity. Korea-Australia Rheology Journal, 22, 259-264. 